\title{
WLB in Zahlen 2016
}

\begin{tabular}{|c|c|}
\hline \multicolumn{2}{|l|}{ Gesamtbestand (Stand: 20.2.2017) } \\
\hline Medienbestand insgesamt & 6.024 .598 \\
\hline \multicolumn{2}{|l|}{ davon: } \\
\hline Buchmaterialien & 3.995 .715 \\
\hline Autographen & 180.531 \\
\hline Handschriften & 15.531 \\
\hline Inkunabeln & 7.092 \\
\hline Noten & 73.340 \\
\hline Karten & 155.763 \\
\hline Mikroformen & 481.313 \\
\hline AV-Materialien (Ton-, Bildträger) & 47.675 \\
\hline CD-ROMS & 27.502 \\
\hline Flugblätter & 160.921 \\
\hline Fotos & 581.116 \\
\hline Plakate & 39.944 \\
\hline Feldpostbriefe & 141.827 \\
\hline Porträts & 36.911 \\
\hline $\begin{array}{l}\text { davon: Varia 3.465, Disketten 3.391, Ortsansichten 8.532, Ansichtskarten 36.823, Ereignisdarstellungen 2.000, } \\
\text { Sonstiges Sig. Nicolai 22.000, Einblattmat./Sonstige 3.048, Nachlässe 158 }\end{array}$ & 79.417 \\
\hline Bibeln (in 658 Sprachen) & 20.322 \\
\hline Lfd. geh. Zeitschriften u. Zeitungen (Abos) & 11.518 \\
\hline Angebot an elektronischen Zeitschriften & 24.927 \\
\hline Angebot an online-Datenbanken & 284 \\
\hline Angebot an E-Books & 32.353 \\
\hline Zugang 2016 & 56.201 \\
\hline Kauf & 21.487 \\
\hline Pflicht & 25.925 \\
\hline Tausch & 364 \\
\hline Geschenk & 8.425 \\
\hline \multicolumn{2}{|l|}{ Benutzung 2016} \\
\hline Öffnungstage & 293 \\
\hline Öffnungsstunden pro Woche & 64 \\
\hline Entleihungen insgesamt & 1.539 .989 \\
\hline Aktive Benutzer & 28.340 \\
\hline Benutzerfälle in den Lesesälen & 214.749 \\
\hline Benutzerschulungen / Führungen (Stunden) & 359 \\
\hline Fernleihbestellungen (aktiv, pos. erledigt) & 35.856 \\
\hline Fernleihbestellungen (passiv, pos. erledigt) & 15.932 \\
\hline Personalstellen 2016 & 129 \\
\hline Kulturelle Veranstaltungen 2016 & 23 \\
\hline Ausstellungen & 5 \\
\hline Weitere Veranstaltungen & 18 \\
\hline
\end{tabular}

